\title{
Antenatal umbilical cord parameters and perinatal outcome
}

\author{
Athira Narayanan*, Priya Ballal, Nikil Shetty, Pralhad Kushtagi \\ Department of Obstetrics \& Gynaecology, Kasturba Medical College, Manipal University, Mangaluru, India
}

Received: 19 February 2016

Accepted: 12 March 2016

\section{*Correspondence:}

Dr. Athira Narayanan,

E-mail: drathirashaji@gmail.com

Copyright: () the author(s), publisher and licensee Medip Academy. This is an open-access article distributed under the terms of the Creative Commons Attribution Non-Commercial License, which permits unrestricted non-commercial use, distribution, and reproduction in any medium, provided the original work is properly cited.

\begin{abstract}
Background: The objective of the study was to study the association between antenatally determined umbilical cord thickness and coiling index at/after 34 weeks of gestation and the measures of perinatal outcome.

Methods: Umbilical cord thickness and coiling index were determined sonographically at or after 34 weeks of gestation in 100 singleton pregnancies. The influence of the antenatal cord findings was analyzed for their associations with measures of perinatal outcome in high and low risk pregnancies. Intrapartum fetal heart rate abnormalities, meconium staining of liquor, birth weight, Apgar score and the need for neonatal intensive care (NICU) admission were considered as measures of perinatal outcome.

Results: Mean cord thickness was $1.62 \pm 0.26 \mathrm{~cm}$ and the coiling index was $0.42 \pm 0.08$ in the present observation of 100 cord sonographies. There were 39 pregnancies with high risk attributes. High risk pregnancies were found to have higher proportion of cases with lean $(<1.3 \mathrm{~cm} ; \mathrm{p}=0.04)$ and hypercoiled cord $(>0.5 ; \mathrm{p}=0.00)$. Among individual associations thicker cord $(>1.9 \mathrm{~cm})$ and macrosomia $(\mathrm{p}=0.01)$, hypercoiled cord and polyhydramnios $(\mathrm{p}=0.02)$ were significant. More number of primigravidas were seen to have hypercoiled cord $(p=0.04)$. Association between cord parameters and meconium stained amniotic fluid, low Apgar score or NICU requirement could not be established.

Conclusions: No association between antenatal umbilical cord characteristics and perinatal outcome was found in pregnancies at high risk for poor perinatal outcome.
\end{abstract}

Keywords: Umbilical cord thickness, Coiling index, Perinatal outcome, Meconium stained amniotic fluid, High risk pregnancy

\section{INTRODUCTION}

Fetal compromise as a major contributor to neonatal morbidity is of great concern for the obstetrician, attending neonatologist, the parturient and her family. Antenatal risk assessment profiles are often insufficient in picking up these cases. It is seen that intrapartum fetal morbidity and mortality are not uncommon even in the low-risk population and fetal acidosis might occur with the same frequency as in the high-risk group. Hence, the reliability of antenatal risk profiles for predicting fetal problems in labour or thereafter are challenged. ${ }^{1}$

Umbilical cord, the lifeline between mother and the fetus is an easily accessible and assessable structure by the ubiquitously used real-time ultrasound. There is some evidence that adverse antenatal and perinatal events could be predicted and/or evaluated by cord thickness and amount of Wharton's jelly, lack of or excess cord coiling, and umbilical vein blood flow patterns. ${ }^{2}$

The umbilical cord is prone to compression or torsion with ensuing interruption of blood flow. It has been accepted that coiling provides protection against these stressors, therefore providing uninterrupted blood supply to the fetus. It was also observed that umbilical cord with area of cross section below the 10th percentile for gestational age, categorized as lean umbilical cord to be significantly associated with the risk of a poor perinatal outcome. $^{3-5}$ 
Present study was planned to find out whether antenatal cord characteristics will contribute to high risk nature of the pregnancy by correlating with determinants of perinatal outcome.

\section{METHODS}

The antenatal assessment of umbilical cord characteristics was carried out at or after 34 weeks of gestation on consenting 100 consecutive well-dated pregnancies booked to deliver at the same hospital.

The facility is a State run District Hospital attached to the Medical College and caters to the referrals for high risk care.

Pregnancies with diabetes (gestational and diagnosed in current pregnancy), hypertension (gestational and preeclampsia), liquor abnormalities (oligo and polyhydramnios) and fetal growth restriction were considered as ones at high risk for poor perinatal outcome.

The non-cephalic presentations, multiple pregnancies, cases with intrauterine fetal demise or single umbilical artery were not considered for the study.

A trans-abdominal ultrasound was performed using a standard ultrasound scanner (PhilipHD7XC machine with $5 \mathrm{MHz}$ transducer). All the measurements were made by single obstetrician trained in obstetric sonography (NS).

1. Measurement of umbilical cord thickness - The image of the cord in close proximity to the abdominal wall but not farther than $0.5 \mathrm{~cm}$ from the abdominal wall insertion was frozen in transverse section. The thickness was measured diagonally between the outer to outer margins in $\mathrm{cm}$. In most cases single measurement was taken. In cases where some tilt was observed while getting cut section of the cord, mean of the diagonally opposite measurements was taken

2. Finding out umbilical cord index (UCI) - was done in a free floating loop of umbilical cord using the inbuilt software. The distance between the coils was measured from the inner edge of an arterial or venous wall to the outer edge of the next coil along the ipsilateral side of the umbilical cord. ${ }^{6}$ The UCI was calculated as the reciprocal value of the distance between a pair of coils

$$
\mathrm{UCI}=1 / \text { distance in } \mathrm{cm}
$$

3. Percentiles were computed for each of the cord parameters studied and $10^{\text {th }}$ and $90^{\text {th }}$ centile values were considered as the cut offs to indicate low or high estimate for the case.
For the purpose of the study - neonatal birth weight below $2.5 \mathrm{~kg}$ was considered as low birth weight and above $4 \mathrm{~kg}$ as macrosomia; APGAR score below 7 at 1 min was considered as low; and any baseline or periodic heart rate changes were taken as non-reassuring patterns as described by National Institute of Child Health and Human Development. ${ }^{7}$

At the time of admission for delivery the cases were categorized as at high or low risk, using the Minnesota system of scoring. ${ }^{8}$ After delivery, the calculated cord parameters were correlated with the determinants of perinatal outcome. The measures of perinatal outcome considered were intrapartum non-reassuring fetal heart rate (FHR) patterns, meconium stained amniotic fluid (MSAF), the Apgar score, neonatal birth weight and requirement of NICU admission.

The obstetric team managing labors were not aware of the antenatal cord characteristics.

The relative risk ratios were used to study the strength of association with at-risk pregnancy, and between cord characteristic and perinatal outcome. For continuous variables to determine significance of observed difference between proportions the Chi Square test and for averages the student - $\mathrm{t}$ tests were used. Statistical significance was set at $95 \%$ level $(\mathrm{p}<0.05)$.

Study was conducted on approval by the Institutional Ethics Committee and all recruited were willing participants with the written consent.

\section{RESULTS}

Of the 100 women studied 39 had high-risk profile. The mean maternal age was $26.6 \pm 4.4$ years and the gestational age $38.5 \pm 3.4$ weeks. Nearly half of the women studied were primigravidas $(52 \%)$ and $45 \%$ t were aged less than 25 years. The mean neonatal birth weight was $2.82 \pm 0.48 \mathrm{~kg}$ with $20 \%$ being low-birth weight. The frequency of caesarean delivery in the study population was $34 \%$.

The conditions attributing high risk nature to the 39 pregnancies were oligohydramnios (9 cases, 23.1\%), polyhydramnios (5 cases, $12.8 \%$ ), fetal growth restriction (14 cases, $35.9 \%$ ), gestational diabetes (8 cases, $20.5 \%$ ), hypertension ( 7 cases, $17.9 \%$ ) and anaemia in one case.

The age and the gestational period at delivery were comparable between the two risk groups and similar was the gravidity/ parity distribution. The babies born to women with high risk characteristics had significantly high proportion $(\mathrm{p}<0.0001)$ of LBW babies and also had significantly low mean birth weight $(\mathrm{p}=0.01)$ than the low risk group. Although, the proportion of cases with MSAF was higher in high risk group, it was not significant $(\mathrm{p}=0.26)$ and the occurrence of non-reassuring fetal heart traces were similar among both the groups (Table 1). 
Table 1: Patient characteristics and perinatal outcome $(\mathrm{N}=100)$.

\begin{tabular}{|c|c|c|c|}
\hline & $\begin{array}{l}\text { High-risk group } \\
(\mathrm{n}=39)\end{array}$ & $\begin{array}{l}\text { Low-risk group } \\
(\mathrm{n}=61)\end{array}$ & Significance \\
\hline $\begin{array}{l}\text { Maternal age in years } \\
(\text { Mean } \pm \text { SD) }\end{array}$ & $26.7(3.9)$ & $26.2(3.9)$ & Paired t 0.523 - test; $\mathrm{p}=0.49$ \\
\hline $\begin{array}{l}\text { Gestational weeks at delivery } \\
(\text { Mean } \pm \text { SD) }\end{array}$ & $37.9(1.1)$ & $37.9(1.1)$ & $\begin{array}{l}\text { Paired t } 0.63206-\text { test; } \\
p=0.528819\end{array}$ \\
\hline Primigravida (n, \%) & $21(53.8 \%)$ & $31(50.8 \%)$ & $\begin{array}{l}\text { Chi Square } 0.01 ; \mathrm{p}=0.92 \\
\text { RR } 1.05 \text { (95\% CI } 0.72-1.55 \text {; } \\
\text { OR } 1.13 \text { (95\% CI } 0.5-2.52)\end{array}$ \\
\hline NR-FHR traces $(\mathrm{n}, \%)$ & $2(5.1 \%)$ & $4(6.6 \%)$ & $\begin{array}{l}\text { Chi } 0.02 ; p=0.88 ; \text { RR } 0.78 \\
(95 \% \text { CI } 0.15-4.06) ; \text { OR } 0.77 \\
(95 \% \text { CI } 0.13-4.41)\end{array}$ \\
\hline $\operatorname{MSAF}(n, \%)$ & $7(17.9 \%)$ & $7(11.5 \%)$ & $\begin{array}{l}\text { Chi Square } 0.38 ; \mathrm{p}=0.26 ; \mathrm{RR} \\
1.56(95 \% \text { CI } 0.59-4.11) ; \mathrm{OR} \\
1.68(95 \% \text { CI } 0.54-5.25)\end{array}$ \\
\hline $\begin{array}{l}\text { Neonatal birth weight in } \mathrm{kg} \\
(\mathrm{Mean} \pm \mathrm{SD})\end{array}$ & $2.66(0.56)$ & $2.93(0.55)$ & Paired t 0.0058 test; $\mathrm{p}=0.012$ \\
\hline $\begin{array}{l}<2.5 \mathrm{~kg}(\mathrm{n}, \%) \\
+4 \mathrm{~kg}(\mathrm{n} \%)\end{array}$ & $17(43.5 \%)$ & $3(4.9 \%)$ & $\begin{array}{l}\text { Chi Square } 19.88 ; \mathrm{p}<0.0001 ; \\
\text { RR } 8.86(95 \% \text { CI } 2.77-28.26) \text {; } \\
\text { OR } 14.93(95 \% \text { CI } 3.98-56.02) \\
\text { Chi sq } 0.17 \cdot \mathrm{p}=0.68\end{array}$ \\
\hline $\pm 4 \mathrm{~kg}(\mathrm{n}, \%)$ & $1(2.070)$ & $1(1.070)$ & Chi Square $0.01 ; p=0.92 ; R R$ \\
\hline $\begin{array}{l}\text { Caesarean deliveries } \\
(\mathrm{n}, \%)\end{array}$ & $14(35.9 \%)$ & $20(32.8 \%)$ & $\begin{array}{l}1.09 \text { (95\% CI } 0.63-1.9) ; \text { OR } \\
1.148 \text { (95\% CI } 0.49-2.62)\end{array}$ \\
\hline
\end{tabular}

SD Standard deviation; NR-FHR Non-reassuring fetal heart rate; MSAF Meconium stained amniotic fluid; RR Relative risk

Table 2: Antenatal umbilical cord characteristics in relation to risk status of pregnancy.

\begin{tabular}{|c|c|c|c|c|}
\hline Cord characteristic & $\begin{array}{l}\text { High risk pregnancy ( } \mathrm{n} \\
=39 \text { ) }\end{array}$ & $\begin{array}{l}\text { Low risk pregnancy } \\
(n=61)\end{array}$ & Significance & \\
\hline $\begin{array}{l}\text { Cord thickness }(\mathrm{n} ; \%) \\
\text { thin }(<1.3 \mathrm{~cm}) \\
\text { thick }(>1.9 \mathrm{~cm}) \\
\text { normal }(1.3-1.9 \mathrm{~cm})\end{array}$ & $\begin{array}{l}3(7.7 \%) \\
3(7.7 \%) \\
33(84.6 \%)\end{array}$ & $\begin{array}{l}1(1.6 \%) \\
6(9.8 \%) \\
54(88.5 \%)\end{array}$ & $\begin{array}{l}x^{2}=0.9 ; p=0.32 \\
x^{2}=0 ; p=1 \\
x^{2}=0.07 ; p=0.79\end{array}$ & $\begin{array}{l}\text { RR 1.34. (95\% CI } \\
0.48-3.69) ; \text { OR } \\
1.4 \text { (95\% CI } 0.4- \\
4.5)\end{array}$ \\
\hline $\begin{array}{l}\text { UCI }(\mathrm{n} ; \%) \\
\text { hypocoiled }(<0.31) \\
\text { hypercoiled }(>0.54) \\
\text { eucoiled }(0.31-0.54)\end{array}$ & $\begin{array}{l}5(7.7 \%) \\
4(17.9 \%) \\
29(74.4 \%)\end{array}$ & $\begin{array}{l}3(8.2 \%) \\
4(4.9 \%) \\
53(86.9 \%)\end{array}$ & $\begin{array}{l}x^{2}=0.08 ; p=0.77 \\
x^{2}=3.16 ; p=0.07 \\
x^{2}=1.75 ; p=0.18\end{array}$ & $\begin{array}{l}\text { RR } 1.19(95 \% \text { CI } \\
0.84-4.52) \\
\text { OR 2.28 (95\% CI } \\
0.81-6.42)\end{array}$ \\
\hline
\end{tabular}

UCI Umbilical Cord Coiling Index; RR Relative risk; RR Relative risk

The observed antenatal cord characteristics showed that the mean thickness was $1.62 \pm 0.26 \mathrm{~cm}$ and the UCI to be $0.42 \pm 0.08$. The calculated $10^{\text {th }}$ and $90^{\text {th }}$ percentile cut offs for thickness were 1.3 and $1.9 \mathrm{~cm}$, respectively. And that for UCI were 0.31 and 0.54 for $10^{\text {th }}$ and $90^{\text {th }}$ centile cut offs, respectively. The proportion of cords with normal thickness (between $1.3-1.9 \mathrm{~cm}$ ) and the eucoiling (between 0.31-0.54 of UCI) was marginally lesser in high risk pregnancy groups (Table 2).

The individual antenatal cord parameters did not show any consistent association between either risk nature of the pregnancy or the measures of pregnancy outcome. Primigravida were found to have more number of hypercoiled cords $(\mathrm{p}=0.04)$. Eight of the 9 hypercoiled cords $(88.9 \% ; \mathrm{p}=0.0)$ and lesser number of hypocoiled cords (3 of 8 cases, 62\%) were noted among high risk groups. The hypercoiled cord were found to have higher number of cases with MSAF than its other counterparts

Lean cord was seen significantly more often in high risk cases ( 3 of 4 cases; $\mathrm{p}=0.04$ ) and thick cords were lesser ( 3 of 9 cases, $33.3 \%$ ) in high risk groups and none of the abnormal FHR traces were seen in abnormal cord thickness groups. 
Table 3: Association between antenatal cord characteristics and perinatal outcome in relation to risk nature of pregnancy.

\begin{tabular}{|c|c|c|c|c|c|}
\hline \multirow{2}{*}{ Perinatal outcome } & \multicolumn{2}{|c|}{ Abnormal cord parameters } & \multicolumn{2}{|c|}{ Normal cord parameters } & \multirow{2}{*}{ Significance } \\
\hline & High-risk & Low risk & High-risk & Low risk & \\
\hline $\operatorname{MSAF}(n=6)$ & $2(66.7 \%)$ & $1(33.3 \%)$ & 0 & $3(100 \%)$ & $\begin{array}{l}\text { RR } 0.3(95 \% \text { CI } \\
0.06-1.6)\end{array}$ \\
\hline NR-FHR $\quad(\mathrm{n}, \%)$ & $2(66.7 \%)$ & $1(33.3 \%)$ & 0 & $6(100 \%)$ & $\begin{array}{l}\text { RR } 0.3(95 \% \text { CI } \\
0.06-1.6)\end{array}$ \\
\hline $\begin{array}{l}\mathrm{LBW}(\mathrm{n}, \%) \\
(\mathrm{Kg} ; \text { Mean } \pm \mathrm{SD})\end{array}$ & $\begin{array}{l}9(90 \%) \\
2.15 \pm 0.2 *\end{array}$ & $\begin{array}{l}1(10 \%) \\
2.4\end{array}$ & $\begin{array}{l}8(80 \%) \\
2.25 \pm 0.14 * *\end{array}$ & $\begin{array}{l}2(20 \%) \\
2.31 \pm 0.12\end{array}$ & $\begin{array}{l}\text { RR } 0.5(95 \% \text { CI } \\
0.05-4.6) ; * \mathrm{t}=-1.9 ; \\
\mathrm{p}=0.13 ; \\
* * \mathrm{t}=0.54 ; \\
\mathrm{p}=0.3\end{array}$ \\
\hline
\end{tabular}

t-test and probability* with abnormal cord parameters** normal cord parameters; MSAF Meconium stained amniotic fluid; NR-FHR Non reassuring fetal heart rate; LBW Low birth weight

There were a total of 52 primigravid women, and were near equally distributed among cases with abnormal cord parameters (53.3 and 46.7 percent of 15 cases among high- and low- risk cohorts, respectively). Among the women with normal antenatal cord characteristics, number of primigravidae was less in high- risk group (35.1 and 64.9 percent of 37 cases in high- and low- risk groups, respectively). The strength of association between cord characteristics and perinatal outcome with respect to risk status, although poor, showed that the pregnancies with antenatal high risk factors had higher proportion of occurrence of MSAF and NR-FHR traces intrapartum and LBW babies. These observations were prevalent among primigravidas (Table 3).

Most of the cases with MSAF (9 of 14, 64.3\%) and babies with low APGAR scores (4 of 5 cases, $80 \%$ ) were noted in normal coiled and normal thickness groups and traces with abnormal FHR pattern in labor was seen equally ( 2 case each) among those with normal and abnormal cord characteristics.

\section{DISCUSSION}

Since many years, the observation of thin cords or ones with a small amount of Wharton's jelly was thought to be associated with adverse perinatal effects or even to the presence of decreased amniotic fluid and low birth weight babies. Wharton's jelly is considered to be protective to the umbilical cord vessels by providing the cushion around them. Hence, any decrease in its amount, due either to extracellular dehydration or the decrease in extracellular matrix can be thought to predispose these vessels to stress, compression or bending. ${ }^{3}$

The studies have shown an association to exist between umbilical cord thickness and cross-sectional area with fetal growth restriction, LBW, or meconium staining. ${ }^{3-5}$ Pregnancies with an early onset of pre-eclampsia were found to have leaner umbilical cords with reduced Wharton's jelly and smaller umbilical vein area. ${ }^{4}$ The present study failed to find any of such associations. Lean cords, however, were found in proportionately higher number in women with antepartum complications. Their association with low birth weight babies or MSAF could not be established. It can conveniently be blamed on lesser number of cases studied. Despite that the authors expected an indication of a trend.

It was thought logical to find significantly larger fetuses in women with gestational diabetes because of larger umbilical cords due to an increase in the amount of Wharton's jelly although in the present study there were only a couple of cases with macrosomia, only one had a thick cord. There are studies with conflicting reports of no association and positive correlation between thicker and larger cord with macrosomia. ${ }^{9,10}$

Statistical correlation of hypocoiled umbilical cord noted very early in second trimester with small for gestational age babies is documented. ${ }^{11}$ But the results from different authors are not uniform. Some have shown an association between UCI and SGA, but did not find any correlation between UCI and a low 5-min Apgar score, not even with SGA by some. ${ }^{2,12}$

Most of the pregnancies with polyhydramnios in the present report had had umbilical cord with hypercoiling ( 3 of $5 ; 60 \% ; \mathrm{p}=0.002$ ). The basis for this association could be that twisting of the umbilical cord is a result of the rotary movement imparted to the embryo, probably increased liquor amnii promotes more rotary movement of the foetus resulting in more coiling. ${ }^{3}$ Although it appears logical, the association was not reproduced. In the present study, hypercoiling of cord was seen in more number of primigravidas (6 of 9 pregnancies; 66.7\%), and found to have an association with hypertension complicating pregnancy. Neither such association nor relation with poor perinatal outcome measures was substantiated consistently. ${ }^{9,12}$ 
The inconsistency in the results obtained could be because, the measurement of coiling across the various studies by the researchers is not uniform, varying from single to several segments, and being made at different periods of gestation, May be because of this reason UCI may be a poor marker when taken as a single parameter to presuppose perinatal outcome. ${ }^{8,11}$ For this reason, we combined both the antenatal umbilical cord parameters to find out association if any with some of the pregnancy or perinatal outcome measures studied. They were measured after 34 weeks of pregnancy. Only single measurements were taken for both thickness and coiling and by a single person.

We feel that at this stage it is imprudent to suggest that antenatal umbilical cord characteristics would help in triaging pregnancies in to the risk groups. It is suggested that more studies especially cohorts of high and low risk pregnancies with uniform measurement technique may provide a reliable inference.

\section{ACKNOWLEDGEMENTS}

Authors thankfully acknowledge the Medical Superintendent and Clinical Heads of Obstetric Units at Government District Lady Goschen Women Hospital, Mangaluru for permitting us to conduct the study.

\section{Funding: Not required}

Conflict of interest: None declared

Ethical approval: The study was approved by the Institutional Ethics Committee

\section{REFERENCES}

1. Kushtagi P, Deepika KS. Amniotic Fluid Index at admission in Labor as predictor of Intrapartum Fetal Status. J Obstet Gynecol. 2011;31:393-5.

2. Predanic M, Perni SC. Absence of a relationship between umbilical cord thickness and coiling patterns. J Ultrasound Med. 2005;24:1491-6.

3. Raio L, Ghezzi F, Di Naro E, Franchi M, Maymon E, Mueller MD. Prenatal diagnosis of a lean umbilical cord : a simple marker for the fetus at risk for being small for gestational age at birth. Ultrasound Obstet Gynecol. 1999; 13:176-80.

4. Raio L, Ghezzi F, Di Naro E, Franchi M, Bolla D, Schneider H. Altered Sonographic Umbilical Cord Morphometry in Early-Onset Preeclampsia. Obstet Gynecol. 2002;100:311-6.

5. Weissman A, Jakobi P, Bronshtein M, Goldstein I. Sonographic measurements of the umbilical cord in pregnancies complicated by gestational diabetes. J Ultrasound Med. 1994;13:11-4.

6. Strong TH, Jarles DL, Vega JS, Feldman DB. The umbilical coiling index. Am J Obstet Gynecol. 1994;170:29-32.

7. Macones GA, Hankins GD, Spong CY, Hauth J, Moore T. The 2008 National Institute of Child Health and Human Development workshop report on electronic fetal monitoring: update on definitions, interpretation, and research guidelines. J Obstet Gynecol Neonatal Nurs. 2008;37:510-5.

8. Edwards LE, Barrada MI, Tatreau RW, Hakanson EY. A Simplified antepartum risk-scoring system. Obstet Gynecol. 1979;54:237-40.

9. Tahmasebi $\mathrm{M}$ and Alighanbari R. Evaluation of Umbilical cord thickness, cross sectional area and coiling index as predictors of pregnancy outcome. Indian J Radiol Imaging. 2011;21:195-8.

10. Cromi A, Ghezzi F, Di Naro E, Siesto G, Bergamini V, Raio L. Large cross-sectional area of the umbilical cord as a predictor of fetal macrosomia. Ultrasound Obstet Gynecol. 2007;30:861-6.

11. Degani S, Leibovich Z, Shapiro I, Gonen R, Ohel G. Early second trimester low umbilical coiling index predicts small-for-gestational age fetuses. J Ultrasound Med. 2001;20:1183-8.

12. Musthafa SJ, Said AB. Association of umbilical coiling index in normal and complicated pregnancies. Diyala Journal of Medicine. 2013;5:1522.

Cite this article as: Narayanan A, Ballal P, Shetty N, Kushtagi P. Antenatal umbilical cord parameters and perinatal outcome. Int J Reprod Contracept Obstet Gynecol 2016;5:1211-5. 